\title{
Interpretation of androgen and anti-Mullerian hormone profiles in a Hispanic cohort of 5- to 8-year-old girls with premature adrenarche
}

Preneet Cheema Brar, MD', Elena Dingle, $\mathrm{MD}^{2}$, Daniela Ovadia, MD ${ }^{3}$, Sarah Pivo, $\mathrm{MD}^{4}$, Veeramac Prasad, PhD', Raphael David, MD ${ }^{1}$

'Division of Pediatric Endocrinology, Department of Pediatrics, New York University School of Medicine, New York, NY, ${ }^{2}$ Department of Pediatrics, Brookdale University Hospital and Medical Center, Brooklyn, NY, ${ }^{3}$ Department of Pediatrics, University of Texas Health Science Center, Houston, TX, ${ }^{4}$ Deparment of Surgery, New York University School of Medicine, New York, NY, USA
Purpose: Premature adrenarche (PA) often leads to polycystic ovary syndrome (PCOS). Higher anti-mullerian hormone (AMH) levels are reported in PCOS. We studied the androgen profile and AMH profiles in Hispanic girls with PA (aged 5-8 years) and age and body mass index (BMI) matched controls.

Methods: Retrospective review of electronic medical records of girls who met the inclusion criteria for premature adrenarche were done.

Results: PA girls $(n=76)$ were matched to control girls $(n=12)$ for age (mean \pm standard deviation) $(6.7 \pm 1$ years vs. $6.2 \pm 1.3$ years $)$ and BMI $\left(20 \pm 10 \mathrm{~kg} / \mathrm{m}^{2}\right.$ vs. $17.8 \pm 2.7 \mathrm{~kg} /$ $\left.\mathrm{m}^{2}\right)$. Dehydroepiandrostenedione sulfate $(63.3 \pm 51.3 \mu \mathrm{g} / \mathrm{dL}$ vs. $29.8 \pm 17.3 \mu \mathrm{g} / \mathrm{dL}$, $P<0.001)$ and testosterone levels $(11.4 \pm 4.8 \mathrm{ng} / \mathrm{dL}$ vs. $8.2 \pm 2.9 \mathrm{ng} / \mathrm{dL}, P=0.001)$ were significantly higher in the PA group than controls. AMH values $(<14$ years: reference range, $0.49-3.15 \mathrm{ng} / \mathrm{mL}$ ) were $3.2 \pm 2.2 \mathrm{ng} / \mathrm{mL}$ vs. $4.6 \pm 3.2 \mathrm{ng} / \mathrm{mL}$ respectively in the PA and control groups and were not different $(P=0.4)$. AMH did not show a correlation with bone age $(P=0.1)$, and testosterone $(P=0.9)$ in the PA group. 17-hydroxyprogesterone levels (17-OHP ng/dL) were $39.5 \pm 30.5 \mathrm{ng} / \mathrm{dL}$ vs. $36.8 \pm 19.8$ $\mathrm{ng} / \mathrm{dL}$ in PA versus control girls. The concentration of $17-\mathrm{OHP}$ was not statistically different between the control and PA groups.

Conclusion: Higher AMH was not observed in PA girls and no correlation with BA and androgen levels was observed.

Keywords: Anti-mullerian hormone, Adrenarche, Polycystic ovary syndrome, Androge

\section{Introduction}

Premature adrenarche $(\mathrm{PA})$ is the result of early activation of the zona reticularis with a Received: 27 March, 2018 Revised: 11 May, 2018 Accepted: 18 August, 2018

Address for correspondence: Preneet Cheema Brar, MD Division of Pediatric Endocrinology, Department of Pediatrics, New York University School of Medicine, 160 East 3nd street, L3, New York 10016, New York, USA

Tel: +1-212-263-5940

Fax: +1-212-263-5808

E-mail: preneet.brar@nyumc.org https://orcid.org/0000-0002-60658328 rise of dehydroepiandrosterone (DHEA), DHEA sulfate (DHEAS), androstenedione and testosterone (T) levels without a rise in cortisol. PA is the appearance of pubic hair (pubarche) and/or body odor in children between 5-8 years of age which is often associated with a rise in DHEAS. ${ }^{1)}$ Biochemical adrenarche is a rise of DHEAS level $\geq 1 \mu \mathrm{mol} / \mathrm{L}(\approx 40 \mu \mathrm{g} / \mathrm{dL})$ whereas clinical adrenarche is the appearance of hyperandrogenism without elevation of androgens. Most girls with PA have normal levels of androgens ${ }^{2,3)}$ though; occasionally they can have values in the early pubertal range. ${ }^{4.5)}$ Even though, PA is known as a benign condition, it's correlation with insulin resistance ${ }^{6-8)}$ and polycystic ovary syndrome (PCOS) has been reported. ${ }^{9-12)}$

There are several triggers for PA which include but are not limited to high BMI, ${ }^{13,14)}$ ovarian hyper-responsiveness to adrenocorticotrophic hormone (ACTH), ${ }^{6}$ history of being small for gestational age. ${ }^{15,16)}$ In vivo and In vitro studies support a role of the insulin/insulin-like growth factor-1 system in adrenarche ${ }^{17)}$ which also has been described in the pathophysiology 
and progression of PCOS. $\left.{ }^{8}\right)$ Nonclassical adrenal hyperplasia (NCAH) due to 21-hydroxylase deficiency is present in $7 \%$ children with premature pubarche. ${ }^{18)}$

Anti-Mullerian hormone (AMH) has been established to be a marker of ovarian follicle reserve, being secreted by preantral follicles (size, 2-5 mm). The preantral follicle number correlates with the elevated androgen levels seen in women with PCOS. ${ }^{19)}$ Two to 3 fold elevated AMH levels have been reported in women with PCOS. ${ }^{19)}$ Twenty percent of children with PA go on to develop PCOS. ${ }^{11)}$ Therefore, the question arises as to whether indices, such as AMH or ovarian morphology, might predict future risk for PCOS. We hypothesized that demonstration of higher AMH levels in girls with PA could serve as a predictor for PCOS

In this retrospective study, we proposed to compare the androgen profile and bone age (BA) of Hispanic girls with PA to age-matched control girls and to evaluate $\mathrm{AMH}$ levels in Hispanic girls with PA.

\section{Materials and methods}

This study was a retrospective chart review study approved by the Institutional Review Board of Health and Hospital Corporation (Bellevue and Woodhull) and New York University School of Medicine. As no personal health information identifiers were used for data collection, the study was an exempt review by the Institutional Review Board and it conformed to the Health Insurance Portability and Accountability Act. The electronic medical records were reviewed by 2 investigators for patient charts coded as "premature adrenarche" and "premature pubarche" for the period between January 2002 and November 2015.

PA was defined as an appearance on exam of pubic or axillary hair, all girls being premenarchal. Exclusion criteria were: (1) $<5$ and $>8$ years in age, (2) signs of central puberty such as premature thelarche and menarche at the time of clinic visit, (3) peripheral precocious puberty, and (4) thyroid illness. Late-onset congenital adrenal hyperplasia was excluded by androgen precursor levels being markedly elevated and in these girls ACTH stimulation was done to establish NCAH using established norms. No adrenal or ovarian ultrasonography was performed. The control group included girls 5-8 years evaluated in our clinic with other endocrinologic disorders. They had androgen levels done for suspected adrenarche but androgen levels were normal for age. Data from 76 Hispanic girls' cases and 12 age and BMI matched controls were analyzed.

Date of the first visit, medical history, body mass index (BMI) and BA were recorded using the Bayley-Pinneau method. ${ }^{20)}$ Weight and height were measured by using a conventional scale and stadiometer. BMI percentiles were assessed using age and sex-specific BMI reference. ${ }^{21)} \mathrm{BA} /$ chronological age was a ratio and if $>1$ was consistent with BA advancement. Blood sampling was conducted at the time of the clinic visit though sampling was done at the same time of the day. Androgen levels and BAs were done as standard of care. AMH levels were done on stored samples which were stored at $-80^{\circ} \mathrm{C}$.

Radioimmunoassay (RIA) of testosterone and DHEAS used an organic solvent extraction and chromatography to eliminate interfering steroids to achieve high assay specificity. Patient serum samples were extracted with ether and subjected to celite partition chromatography using ethylene glycol as stationary phase and varying concentrations of ethyl acetate in isooctane as a mobile phase. Sensitivity of the assay for testosterone was $4 \mathrm{pg} /$ tube and the mean intra- and interassay variation for $\mathrm{T}$ was $6.3 \%$ and $7.8 \%$, respectively in the range of $5-30 \mathrm{pg} / \mathrm{tube}^{22)}$ (MP Biomedicals, Solon, OH, USA). RIA for DHEAS was directly performed on a highly diluted serum sample without extraction or purification. The sensitivity of the assay for DHEAS was $6 \mathrm{pg} /$ tube with an intra- and interassay variation of $7.1 \%$ and $8.3 \%$, respectively (MP Biomedicals). $17-\mathrm{OH}$ progesterone was done by RIA after extraction and purification by liquid-liquid chromatography on celite. Antibody was from MP Biomedicals and the tritiated tracer used for competitive binding was from American Radiochemical (St. Louis, MO, USA). Androstenedione was done at Quest using liquid chromatography/Tandem Mass Spectrometry. AMH samples were analyzed by conventional Gen II Assay. ${ }^{23)}$ The test method has been described in previous reference. ${ }^{24)}$ The lowest amount of $\mathrm{AMH}$ in a sample that can be detected with a $95 \%$ probability was calculated to be $0.08 \mathrm{ng} / \mathrm{mL}$ and intra- and interassay coefficient of variation were $5.3 \%-11.4 \%$ and $3.8 \%-17.3 \%$, respectively. ${ }^{25)}$ Hagen et al. ${ }^{26)}$ has reported the normal reference range for AMH for children and adolescents $<14$ years

Data were analyzed with IBM SPSS Statistics ver. 22.0 (IBM Co., Armonk, NY, USA). A $P$-value $<0.05$ was used to infer statistical significance. Kolgomorov-Smirnov and ShapiroWilks tests were used to examine the normality of distribution of the variables. For univariate analysis there were 2 groups: girls with PA and age-matched Hispanic girls. Anthropometric measurements (age, height, and BMI), BA, BA/chronological ratio (BA/CA), androgen profile (testosterone, DHEAS, 17 $\mathrm{OH}$ progesterone, and androstenedione) and $\mathrm{AMH}$ levels were compared between the 2 groups using 2 -sample Student $t$-test or Wilcoxon rank sum test depending on the normality of distribution. Pearson or Spearman correlation coefficients were used to examine the linear or rank order relationship between variables of interest such as anthropometric data, BA, androgen profile, and AMH levels.

\section{Results}

PA girls $(n=76)$ were matched to control girls $(n=12)$ for age (mean \pm standard deviation $[\mathrm{SD}])(6.7 \pm 0.9$ years vs. $6.2 \pm 1.3$ years $)$ and BMI $\left(20.1 \pm 10.1 \mathrm{~kg} / \mathrm{m}^{2}\right.$ vs. $\left.17.8 \pm 2.7 \mathrm{~kg} / \mathrm{m}^{2}\right)$. BA and $\mathrm{BA} / \mathrm{CA}$ at diagnosis were $7.7 \pm 1.5$ years vs. $6.4 \pm 1.5$ years and $1.2 \pm 0.2$ years vs. $1 \pm 0.2$ years, respectively (Table 1 ).

Testosterone levels (reference range for prepubertal girls: $<10$ $\mathrm{ng} / \mathrm{dL}$ ) were done in 66 of 76, DHEAS (5-8 years: reference range, $9-75 \mu \mathrm{g} / \mathrm{dL}) 68$ of 76 and $\mathrm{AMH}(<14$ years: reference 
range, $0.49-3.15 \mathrm{ng} / \mathrm{mL}) 33$ of 76 of the girls with PA. In the control group testosterone, DHEAS were available for all girls, AMH could be done only in 6 of 12 girls. DHEAS $(63.3 \pm 51.3$ $\mu \mathrm{g} / \mathrm{dL}$ vs. $29.8 \pm 17.3 \mu \mathrm{g} / \mathrm{dL}, P<0.001)$ and testosterone levels $(11.4 \pm 4.8 \mathrm{ng} / \mathrm{dL}$ vs. $8.2 \pm 2.9 \mathrm{ng} / \mathrm{dL} ; P=0.001)$ were different in the PA and control groups. Among the girls with PA, 17-OHP levels were reported in 68 of the 76 girls $(39.5 \pm 30.5 \mathrm{ng} / \mathrm{dL}$ vs. $36.8 \pm 19.8 \mathrm{ng} / \mathrm{dL}, P=0.15)$ while androstenedione levels were reported in 30 of the 76 girls $(27.9 \pm 23.4 \mathrm{ng} / \mathrm{dL})$.

Testosterone levels were elevated above the established lab reference range for our RIA assay in 64\% (42 of 66) of girls with PA compared to $25 \%$ of girls in the control group. DHEAS was elevated in 19\% (13 of 68) of girls with PA compared to no girl in the control group. DHEAS correlated with height $(r=0.3, P=0.03)$ and $\mathrm{BA}(r=0.3, P=0.02)$ (Fig. 1) using a Pearson correlation.

AMH values were $3.19 \pm 2.24$ (range, $0.068-8.8$ ) and $4.7 \pm 2.7$ $\mathrm{ng} / \mathrm{mL}$ in the PA $(\mathrm{n}=33)$ and control group $(\mathrm{n}=6)$, respectively. AMH level did not show any association with either DHEAS $(P=0.2)$, testosterone $(P=0.9)$ or BA $(P=0.1)$ in girls with PA.

\section{Discussion}

In this study, the DHEAS and testosterone were higher in PA girls compared to controls, but there were no differences in the 17-OHP between the 2 groups. DHEAS have been higher in girls with PA compared to normal timed girls. ${ }^{5,15)}$ while other studies have shown DHEAS levels being within reference range for age. ${ }^{27)}$ Dorn et al. ${ }^{5)}$ showed testosterone above detection limit in 56\% of girls with PA compared to $23 \%$ in age-matched girls $(P=0.004)$ using RIA methodology (most girls had values

Table 1. Basic characteristics of the study groups

\begin{tabular}{lccc}
\hline Characteritic & $\begin{array}{c}\text { PA group } \\
(n=76)\end{array}$ & $\begin{array}{c}\text { Control group } \\
(n=12)\end{array}$ & P-value \\
\hline Age $(\mathrm{yr})$ & $6.7 \pm 0.9$ & $6.2 \pm 1.3$ & $\mathrm{NS}$ \\
Height $(\mathrm{cm})$ & $123.9 \pm 7.7$ & $123 . \pm 7.8$ & $\mathrm{NS}$ \\
Weight $(\mathrm{kg})$ & $28.8 \pm 8.4$ & $24.4 \pm 3.8$ & $\mathrm{NS}$ \\
Height/age & $7.5 \pm 0.9$ & $6.3 \pm 1$ & $\mathrm{NS}$ \\
BMl $\left(\mathrm{kg} / \mathrm{m}^{2}\right)$ & $20.1 \pm 10.1$ & $17.8 \pm 2.7$ & $\mathrm{NS}$ \\
BMI percentile & $74.9 \pm 28.5$ & $79.7 \pm 21.9$ & $\mathrm{NS}$ \\
Bone age $(\mathrm{yr})$ & $7.7 \pm 1.5$ & $6.4 \pm 1.5$ & $\mathrm{NS}$ \\
BA/CA & $1.2 \pm 0.2$ & $1 \pm 0.2$ & $\mathrm{NS}$ \\
Testosterone total $(\mathrm{ng} / \mathrm{dL})$ & $11.4 \pm 4.8$ & $8.2 \pm 2.9$ & 0.001 \\
DHEA-S ( $\mu \mathrm{gg} / \mathrm{dL})$ & $63.3 \pm 51.3$ & $29.8 \pm 17.3$ & $<0.001$ \\
17-Hydroxyprogesterone $(\mathrm{ng} / \mathrm{dL})$ & $39.5 \pm 30.5$ & $36.8 \pm 19.8$ & $\mathrm{NS}$ \\
Androstenedione $(\mathrm{ng} / \mathrm{dL})$ & $27.9 \pm 23.4$ & $\mathrm{NA}$ & - \\
AMH $(0.49-3.15 \mathrm{ng} / \mathrm{mL})$ & $3.2 \pm 2.2$ & $4.6 \pm 3.2^{*}$ & - \\
\hline N & &
\end{tabular}

$\mathrm{N}$ varies for both cases and controls for variables of interest. Values are presented as mean \pm standard deviation.

PA, premature adrenarche; BMI, body mass index; $\mathrm{BA}$, bone age; CA, chronological age; DHEAS, dehydroepiandrosterone; $\mathrm{AMH}$, anti-Mullerian hormone; NS, not significant; NA, not available.

"No t-test for AMH between the groups was done due to low $\mathrm{N}$ in the control group. below the detection limit. Our results align with this group in that $65 \%$ our PA cohort had above lab reference testosterone levels. Uçar et al. ${ }^{28)}$ also demonstrated higher testosterone levels (45.1 pmol/L vs. $31.2 \mathrm{pmol} / \mathrm{L}, P=0.001)$ in Turkish girls with PA ( $n=56)$ when compared to control girls $(n=33)$ using an RIA assay similar to ours. On the other hand, Paterson et al. ${ }^{27)}$ did not find elevated testosterone in Scottish girls when compared to normal reference range using a chemiluminescent assay (mean $+\mathrm{SD}$ [range]). Dorn et al. ${ }^{5)}$ reported mildly elevated androstenedione within the reference range, while elevated 17OHP has not been reported in PA and more consistent with the diagnosis of NCAH. Elevation of testosterone in girls with PA may be to be driven by age, ethnicity (Hispanic vs. Turkish vs. White) and assay use. Age and ethnicity affect the age of onset of adrenarche as shown the National health examination study (Third National Health and Nutrition Examination Survey). ${ }^{29)}$ Immunoassays like a sensitive RIA (as the one used by our Endocrine lab) have been compared to mass spectrometry and have good correlation for detection of low testosterone levels in prepubertal girls. ${ }^{30)}$ Longitudinal follow up in PA girls with elevated testosterone level on diagnosis may show to have predictive value for future development of PCOS.

Our results show that Hispanic girls with PA have minimal BA advancement, which is not different from age-matched controls. This result is in contrast to the result of previous studies that BA advancement was observed in PA children. Sopher et al. have shown that BA is often advanced in girls with PA and 30\% will have advancement of $>2$ years. ${ }^{31-34)}$ DeSalvo et al. $^{33)}$ showed that even though girls with PA were taller and heavier their final height was just above their midparental height and the authors speculated that the effects of an advanced BA on final height were minor.

Our results show that Hispanic girls with PA do not have

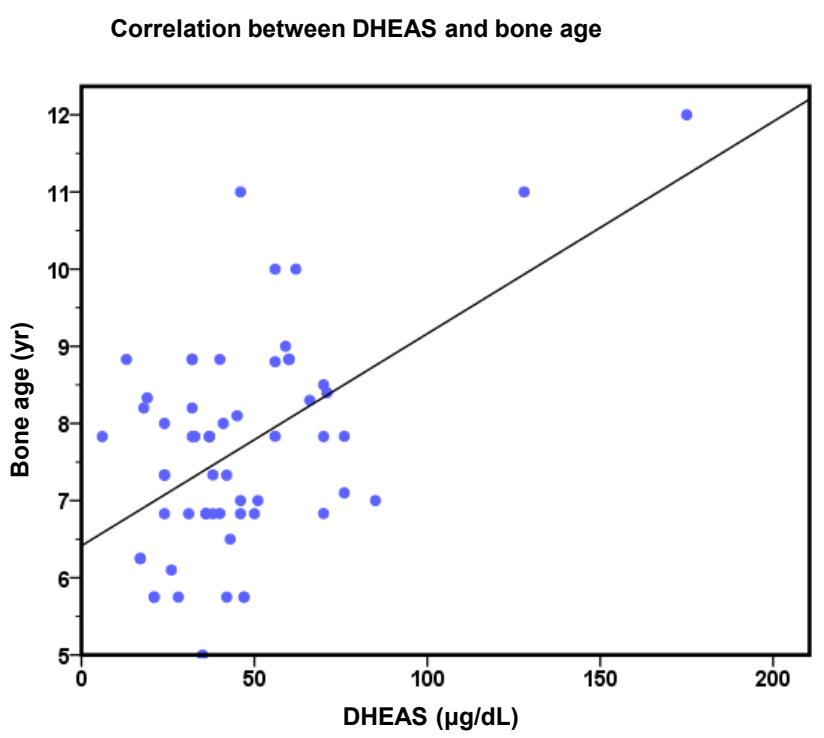

Fig. 1. Pearson correlation (linear regression); $P=0.006, r=0.034$. DHEAS, dehydroepiandrostenedione sulphate. 
elevated AMH levels. During childhood and adolescence, AMH fluctuations are minimal, and each girl maintains her relative level during pubertal transition. AMH levels start to rise by much as $17 \%$ three years before puberty and declines by $30 \%$ within the first 2 years of puberty. Several studies have reported higher AMH levels in women with PCOS.$^{35-37)}$ Crisosto et al. ${ }^{38)}$ showed higher (AMH) levels in prepubertal and peripubertal daughters of PCOS women, suggesting that these girls may have an altered follicular development which starts early in development and continues through puberty. However, there is no correlation between the level of AMH before pubertal onset and age at entering puberty. ${ }^{26)}$ Since there are many studies that report a high incidence of PCOS in girls with PA, this study attempted to verify if the AMH level is higher in PA girls. One study with Scottish girls reports that the AMH level is higher in PA girls, and 3 studies including this study (Uçar, Utriainen, and this study) report that there is no difference in AML level between the 2 groups. ${ }^{27,28,39)}$ Two of the 3 studies reporting no difference in AMH levels (Ucar and this study) showed no difference in BMI between the 2 groups, but Utriainen's study found a significant difference in the BMI between the 2 groups in and compared the AMH level while controlling the BMI. In the Scottish study, the difference in BMI cannot be verified because there is no detailed description of the anthropometric value of the control group. ${ }^{27)}$ Therefore, there seems to be no difference in the AMH level in prepubertal PA girls in a few studies that have been reported until now including this study. Additional research is necessary to assess to determine whether the AMH level gradually increases after the beginning of puberty in PA girls, and if it increases, whether this is correlated with the occurrence of PCOS later on.

We had several limitations in our study. First, it is a relatively small cohort with few controls; further studies with a larger population are needed in order to have a more precise conclusion regarding the association between $\mathrm{AMH}$ and PA. We also recognize that the AMH Gen II used in this study was the conventional and not revised assay which is more sensitive than the older version. Furthermore, the fact that our findings are of Hispanic girls brings into question the generalizability of our information. Our study is the first of its kind to study the AMH levels in the Hispanic ethnic cohort of girls with PA. We did match the PA girls for age and BMI controls and used sensitive assays for variables of interest. These are positive aspects of our study design.

In this study, we demonstrated that serum AMH was not elevated in prepubertal Hispanic girls with PA, and AMH levels were not associated with androgen profile or BA in prepubertal Hispanic girls. A longitudinal study on biochemical markers (serial AMH, androgens, gonadotropins) and pelvic ultrasonography is necessary for PA girls in pubertal ages before the start of menstruation as well as in prepubertal ages.

\section{Conflict of interest}

No potential conflict of interest relevant to this article was reported.

\section{References}

1. Leung AK, Robson WL. Premature adrenarche. J Pediatr Health Care 2008;22:230-3.

2. Liimatta J, Laakso S, Utriainen P, Voutilainen R, Palvimo JJ, Jääskeläinen T, et al. Serum androgen bioactivity is low in children with premature adrenarche. Pediatr Res 2014;75:645-50.

3. Voutilainen R, Jääskeläinen J. Premature adrenarche: etiology, clinical findings, and consequences. J Steroid Biochem Mol Biol 2015;145:226-36.

4. Montalto J, Yong AB, Funder JW, Connelly JF. Serum 5 -androstene- 3 beta, 17 beta-diol sulphate, sex hormone binding globulin and free androgen index in girls with premature adrenarche. J Steroid Biochem 1989;33:1149-54.

5. Dorn LD, Rose SR, Rotenstein D, Susman EJ, Huang B, Loucks TL, et al. Differences in endocrine parameters and psychopathology in girls with premature adrenarche versus on-time adrenarche. J Pediatr Endocrinol Metab 2008;21:439-48.

6. Ibáñez L, Potau N, Zampolli M, Riqué S, Saenger P, Carrascosa A. Hyperinsulinemia and decreased insulin-like growth factor-binding protein-1 are common features in prepubertal and pubertal girls with a history of premature pubarche. J Clin Endocrinol Metab 1997;82:2283-8.

7. Ibáñez L, Potau N, Chacon P, Pascual C, Carrascosa A. Hyperinsulinaemia, dyslipaemia and cardiovascular risk in girls with a history of premature pubarche. Diabetologia 1998;41:1057-63.

8. Silfen ME, Manibo AM, Ferin M, McMahon DJ, Levine LS, Oberfield SE. Elevated free IGF-I levels in prepubertal Hispanic girls with premature adrenarche: relationship with hyperandrogenism and insulin sensitivity. J Clin Endocrinol Metab 2002;87:398-403.

9. Banerjee S, Raghavan S, Wasserman EJ, Linder BL, Saenger P, DiMartino-Nardi J. Hormonal findings in AfricanAmerican and Caribbean Hispanic girls with premature adrenarche: implications for polycystic ovarian syndrome. Pediatrics 1998;102:E36.

10. Kousta E. Premature adrenarche leads to polycystic ovary syndrome? Long-term consequences. Ann N Y Acad Sci 2006;1092:148-57.

11. Ibañez L, Potau N, Virdis R, Zampolli M, Terzi C, Gussinyé $\mathrm{M}$, et al. Postpubertal outcome in girls diagnosed of premature pubarche during childhood: increased frequency of functional ovarian hyperandrogenism. J Clin Endocrinol Metab 1993;76:1599-603.

12. Ibáñez L, Jaramillo A, Enríquez G, Miró E, López-Bermejo A, Dunger D, et al. Polycystic ovaries after precocious 
pubarche: relation to prenatal growth. Hum Reprod 2007; 22:395-400.

13. Rosenfield RL, Lipton RB, Drum ML. Thelarche, pubarche, and menarche attainment in children with normal and elevated body mass index. Pediatrics 2009;123:84-8.

14. Gavela-Pérez T, Garcés C, Navarro-Sánchez P, López Villanueva L, Soriano-Guillén L. Earlier menarcheal age in Spanish girls is related with an increase in body mass index between pre-pubertal school age and adolescence. Pediatr Obes 2015;10:410-5.

15. Ibáñez L, Potau N, Marcos MV, de Zegher F. Exaggerated adrenarche and hyperinsulinism in adolescent girls born small for gestational age. J Clin Endocrinol Metab 1999;84:4739-41.

16. Hokken-Koèlega AC. Timing of puberty and fetal growth. Best Pract Res Clin Endocrinol Metab 2002;16:65-71.

17. Zhang LH, Rodriguez H, Ohno S, Miller WL. Serine phosphorylation of human P450c17 increases 17,20-lyase activity: implications for adrenarche and the polycystic ovary syndrome. Proc Natl Acad Sci U S A 1995;92:1061923.

18. Ibáñez L, Bonnin MR, Zampolli M, Prat N, Alia PJ, Navarro MA. Usefulness of an ACTH test in the diagnosis of nonclassical 21-hydroxylase deficiency among children presenting with premature pubarche. Horm Res 1995;44:51-6.

19. Pigny P, Merlen E, Robert Y, Cortet-Rudelli C, Decanter C, Jonard S, et al. Elevated serum level of anti-mullerian hormone in patients with polycystic ovary syndrome: relationship to the ovarian follicle excess and to the follicular arrest. J Clin Endocrinol Metab 2003;88:5957-62.

20. Bayley N, Pinneau SR. Tables for predicting adult height from skeletal age: revised for use with the Greulich-Pyle hand standards. J Pediatr 1952;40:423-41.

21. Kuczmarski RJ, Ogden CL, Guo SS, Grummer-Strawn LM, Flegal KM, Mei Z, et al. 2000 CDC Growth Charts for the United States: methods and development. Vital Health Stat 11 2002:1-190.

22. Collins WP, Mansfield MD, Alladina NS, Sommerville IF. Radioimmunoassay of plasma testosterone. J Steroid Biochem 1972;3:333-48.

23. Kumar A, Kalra B, Patel A, McDavid L, Roudebush WE. Development of a second generation anti-Müllerian hormone (AMH) ELISA. J Immunol Methods 2010;362:519.

24. Vaiarelli A, Drakopoulos P, Blockeel C, De Vos M, van de Vijver A, Camus M, et al. Limited ability of circulating anti-Müllerian hormone to predict dominant follicular recruitment in PCOS women treated with clomiphene citrate: a comparison of two different assays. Gynecol Endocrinol 2016;32:227-30.

25. Wallace AM, Faye SA, Fleming R, Nelson SM. A multicentre evaluation of the new Beckman Coulter anti-Mullerian hormone immunoassay (AMH Gen II) Ann Clin Biochem 2011;48(Pt 4):370-3.
26. Hagen CP, Aksglaede L, Sørensen K, Mouritsen A, Andersson AM, Petersen $\mathrm{JH}$, et al. Individual serum levels of anti-Müllerian hormone in healthy girls persist through childhood and adolescence: a longitudinal cohort study. Hum Reprod 2012;27:861-6.

27. Paterson WF, Ahmed SF, Bath L, Donaldson MD, Fleming R, Greene SA, et al. Exaggerated adrenarche in a cohort of Scottish children: clinical features and biochemistry. Clin Endocrinol (Oxf) 2010;72:496-501.

28. Uçar A, Erol OB, Yekeler E, Yildiz I, Bozlak S, Saka N, et al. Pelvic ultrasound findings in prepubertal girls with precocious adrenarche born appropriate for gestational age. Clin Endocrinol (Oxf) 2014;80:699-705.

29. Wu T, Mendola P, Buck GM. Ethnic differences in the presence of secondary sex characteristics and menarche among US girls: the Third National Health and Nutrition Examination Survey, 1988-1994. Pediatrics 2002;110:752-7.

30. Ankarberg-Lindgren C, Norjavaara E. Sensitive RIA measures testosterone concentrations in prepubertal and pubertal children comparable to tandem mass spectrometry. Scand J Clin Lab Invest 2015;75:341-4.

31. Diaz A, Bhandari S, Sison C, Vogiatzi M. Characteristics of children with premature pubarche in the new york metropolitan area. Horm Res 2008;70:150-4.

32. Sopher AB, Thornton JC, Silfen ME, Manibo A, Oberfield SE, Wang J, et al. Prepubertal girls with premature adrenarche have greater bone mineral content and density than controls. J Clin Endocrinol Metab 2001;86:5269-72.

33. DeSalvo DJ, Mehra R, Vaidyanathan P, Kaplowitz PB. In children with premature adrenarche, bone age advancement by 2 or more years is common and generally benign. J Pediatr Endocrinol Metab 2013;26:215-21.

34. Sopher AB, Jean AM, Zwany SK, Winston DM, Pomeranz $\mathrm{CB}$, Bell JJ, et al. Bone age advancement in prepubertal children with obesity and premature adrenarche: possible potentiating factors. Obesity (Silver Spring) 2011;19:125964 .

35. Bhide P, Homburg R. Anti-Müllerian hormone and polycystic ovary syndrome. Best Pract Res Clin Obstet Gynaecol 2016;37:38-45.

36. Qi X, Pang Y, Qiao J. The role of anti-Müllerian hormone in the pathogenesis and pathophysiological characteristics of polycystic ovary syndrome. Eur J Obstet Gynecol Reprod Biol 2016;199:82-7.

37. Łebkowska A, Kowalska I. Anti-Müllerian hormone and polycystic ovary syndrome. Endokrynol Pol 2017;68:74-8.

38. Crisosto N, Codner E, Maliqueo M, Echiburú B, Sánchez F, Cassorla F, et al. Anti-Müllerian hormone levels in peripubertal daughters of women with polycystic ovary syndrome. J Clin Endocrinol Metab 2007;92:2739-43.

39. Utriainen P, Jääskeläinen J, Voutilainen R. Serum antimüllerian hormone concentrations in prepubertal girls with and without premature adrenarche: The influence of body mass index. Horm Res Paediatr 2010;74:207-11. 